\title{
periferio
}

\section{A EDUCAÇÃO ESCOLAR DE CRIANÇAS E JOVENS COM DEFICIÊNCIA COMO QUESTÃO}

\author{
Eveline Algebaile ${ }^{1}$ \\ Universidade do Estado do Rio de Janeiro \\ Luiz Antonio de Souza ${ }^{2}$ \\ Secretaria Municipal de Educação do Rio de Janeiro
}

\section{Resumo}

Neste artigo, busca-se discutir a questão da educação escolar de crianças e jovens com deficiência, no Brasil, considerando-se os processos por meio dos quais diferentes aspectos da vida coletiva são elaborados como problemas da vida pública, constituindo-se como "questões" socialmente reconhecidas. 0 termo "questão" é entendido, neste caso, como obrigatoriamente relacionado ao modo como uma sociedade se indaga sobre suas condições e disposições em relação ao convívio com determinados conjuntos de problemas ou ao seu enfrentamento. Tendo essa discussão geral como base, são apresentados alguns delineamentos históricos relevantes assumidos por essa questão, no Brasil, com ênfase nas suas reconfigurações a partir da década de 1990 e, especialmente, da formulação da Política Nacional de Educação Especial na Perspectiva da Educação Inclusiva (2008). São destacados, neste caso, aspectos relacionados ao modo de entendimento da questão na Política Nacional, definido na noção de educação especial inclusiva, bem como aspectos relacionados às experiências concretas de sua implantação e implementação nos estados e municípios, entendendo-se que esses aspectos expressam impasses e desafios necessários de serem conhecidos e enfrentados para que os direitos educacionais das crianças e jovens com deficiência possam se tornar um elemento efetivamente referenciador das políticas nesse âmbito.

Palavras-chave: educação especial; educação inclusiva; educação escolar; políticas públicas

\footnotetext{
1 Professora Associada da Faculdade de Formação de Professores (FFP) da Universidade do Estado do Rio de Janeiro (UERJ). Professora do Programa de Pós-Graduação em Políticas Públicas e Educação (PPFH) e Procientista da UERJ. ealgebaile@gmail.com

2 Professor da Rede Pública Municipal de Ensino do Rio de Janeiro.
} 


\title{
periferio
}

\author{
THE SCHOOL EDUCATION OF CHILDREN AND \\ YOUNG PEOPLE WITH DESABILITIES AS QUESTION
}

\begin{abstract}
In this article, we seek to discuss the question of school education of children and young with disabilities, in Brazil, considering the processes through which different aspects of collective life are elaborated as issues of public life, constituting itself as "questions" are socially recognized. The term "question" is understood, in this case, as necessarily related to how a society that asks about their conditions and provisions in relation to the associations with particular sets of problems or to your confrontation. Having this general discussion as a basis, are presented some designs relevant historical assumed by this question, in Brazil, with emphasis on its reconfiguration from the 1990 s and, especially, the formulation of a National Policy of Special Education in the perspective of Inclusive Education (2008). Are highlighted, in this case, aspects related to the way of understanding the question in National Politics, defined in the concept of inclusive special education, as well as aspects related to concrete experiences your deployment and implementation in the states and counties, understanding that these aspects express impasses and challenges needed to be known and faced to the educational rights of children and young people with disabilities can become an element effectively referrer of policies within this scope.
\end{abstract}

Keywords: Special education; Inclusive education; School education; Public policy 


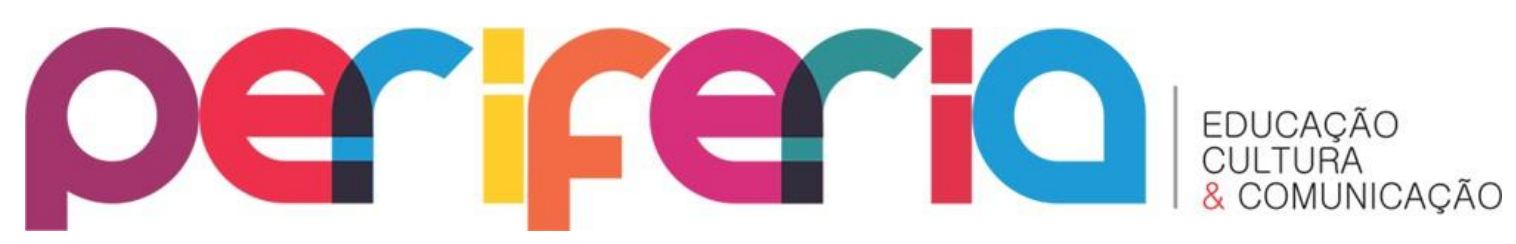

\section{INTRODUÇÃO}

A inclusão de crianças e jovens com deficiência na escola regular se apresenta, atualmente, como um importante ponto de tensão no debate sobre a escola pública brasileira. As disposições iniciais da Lei de Diretrizes e Bases da Educação Nacional de 1996 - LDB/96 (BRASIL, 1996) - a respeito, bem como seus desdobramentos, em termos das novas disposições normativas sobre 0 tema e das experiências institucionais relacionadas à implantação e implementação de políticas orientadas pelas novas definições e normas, deram maior visibilidade a aspectos e impasses da escolarização pública e das condições de exercício de direitos relacionados à educação antes mais encobertos ou secundarizados. No mesmo contexto, a demanda efetiva pelo atendimento educacional de crianças e jovens com deficiência foi se modificando substantivamente, não apenas em termos quantitativos, mas também em termos dos novos requerimentos projetados tanto sobre a escola quanto sobre outros âmbitos de políticas públicas, como especialmente a assistência social e a saúde.

Essa alteração do quadro em que o atendimento educacional de crianças e jovens com deficiência é problematizado e praticado implica uma substantiva modificação dos desafios teóricos e práticos relacionados ao tema, reconfigurando e dando novo peso e nova posição social, acadêmica e política ao que podemos nomear de "a questão da educação escolar das crianças e jovens com deficiência".

Neste artigo, partindo da discussão das formas e condições a partir das quais um aspecto da vida antes entendido como pertinente à esfera privada passa a ser tratado como "problema pertinente à vida pública" (TELLES, 2001), procuramos analisar alguns delineamentos assumidos pela questão da educação escolar de crianças e jovens com deficiência, no Brasil, a partir década de 1990, bem como apresentar e discutir alguns de seus aspectos e impasses que estão se tornando mais intensos e visíveis a partir das 


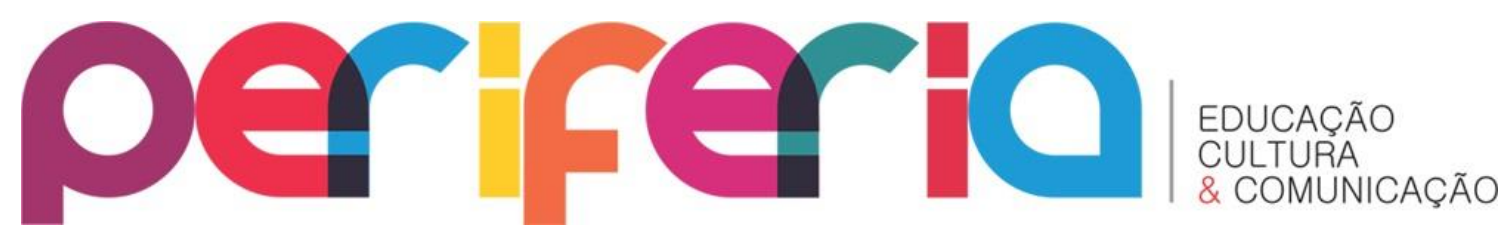

experiências concretas de implantação e implementação da chamada "educação especial inclusiva".

\section{DO PONTO DE VISTA SOCIAL E POLÍTICO, O QUE É UMA “QUESTÃO”?}

A análise de políticas públicas referidas a direitos requer a consideração prévia da história do direito (ou direitos) a que cada política se refere. Por mais incipiente que uma política possa parecer, sua existência já é, por si, uma espécie de documento que atesta a ocorrência precedente de processos por meio dos quais certo aspecto da vida social, antes entendido como pertinente ao âmbito privado, passa a ser percebido em termos de suas implicações com a vida coletiva e vai sendo socialmente elaborado como problema da vida pública (TELLES, 2001).

Essa passagem, em geral, é lenta e acidentada. Primeiro, porque implica alterações culturais relacionadas à prática social e aos modos de entender determinados problemas na sua dinâmica interna e nas suas formas de vínculo com a vida coletiva. Segundo porque essas alterações culturais não se dão como revelações mágicas da pertinência e justeza das coisas. Elas se dão ao longo de processos, tensionadas por disputas entre forças sociais e políticas $^{3}$ distintas e pressionadas pela hegemonia de certas formas de pensar e agir, incluindo a utilização desigual dos meios de difusão de informações e

\footnotetext{
${ }^{3}$ Apoiamo-nos, aqui, nas formulações de Antonio Gramsci (2000a, 2000b e 2002) sobre a necessidade de que a investigação histórico-social leve em conta, como elemento central, as forças sociais e as forças políticas em relação em cada contexto. Dessas formulações, é possível depreender, sinteticamente, que, para o autor, o termo "forças sociais" designa os variados agrupamentos sociais relacionados às diversas posições dos sujeitos no processo de produção de sua existência, enquanto o termo "forças políticas" designa os sujeitos coletivos constituídos pelas associações intencionais de sujeitos de um mesmo grupo ou de grupos afins em torno de interesses, questões, lutas e projetos comuns, ainda que essas associações apresentem, entre si e no curso da história, diferenciados graus de coesão e homogeneidade. $\mathrm{Na}$ análise das relações de força proposta por Gramsci, é necessário atenção para as diferentes escalas (internacional, nacional, regional, local...) em que se organizam e relacionam determinadas forças, bem como atenção para a modificação de seus pesos e de suas formas de articulação, agregação ou confronto.
} 


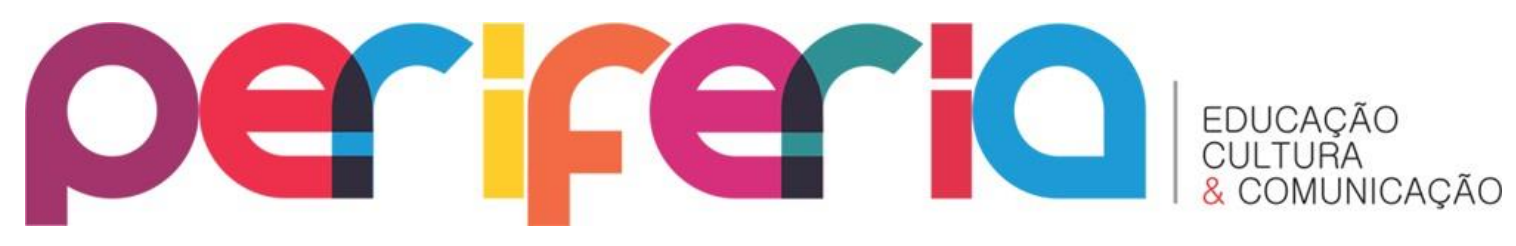

de convencimento, que, como mostra Gramsci (2000a), podem conter a compreensão de certos fatos, fenômenos e problemas em quadros já estabelecidos, tratando-os predominantemente segundo perspectivas conservadoras, e mesmo os distorcendo, de modo a subordinar sua discussão pública aos termos hegemônicos.

Tem-se com isto que a passagem de um tema da esfera privada para a esfera pública implica obrigatoriamente a emergência e a eclosão de disputas políticas que, em geral, não se dão se antes e simultaneamente não ocorrerem alterações substantivas na própria composição da sociedade, implicando mudanças nas características, posições e pesos das forças sociais e políticas capazes de expressar e disputar publicamente uma mudança de concepção que leve ao reconhecimento de um novo "direito".

De outro lado, como a afirmação de um novo direito pode implicar a alteração de outros direitos já convencionados, podendo envolver deslocamentos de prioridades e revogações de status e prerrogativas que mexem com os interesses dos diferentes grupos, a luta política pela emergência e consolidação de um direito não diz respeito apenas à capacidade de uma sociedade atribuir justeza e pertinência a algo que está sendo pleiteado por um grupo. Diz respeito, fundamentalmente, a como essa sociedade hierarquiza valores e prerrogativas, distribuindo diferenciadamente e regulando o acesso a garantias e condições (FOUCAULT, 2008), e definindo aquilo que pode tolerar sem colocar em risco suas condições e seu regime de coesão (CASTEL, 1998).

É a consideração dessa dinâmica que nos leva a entender que, do ponto de vista social e político, o termo "questão", que comumente delimita âmbitos de discussão de problemas da vida pública - a questão social, a questão educacional, a questão urbana -, não deve designar formas específicas de problemas da vida social, mas, como bem percebido por Castel (1998 e 2008), deve assinalar o modo como uma sociedade se indaga sobre suas condições e disposições em relação ao convívio com determinados conjuntos de problemas ou ao seu enfrentamento. 


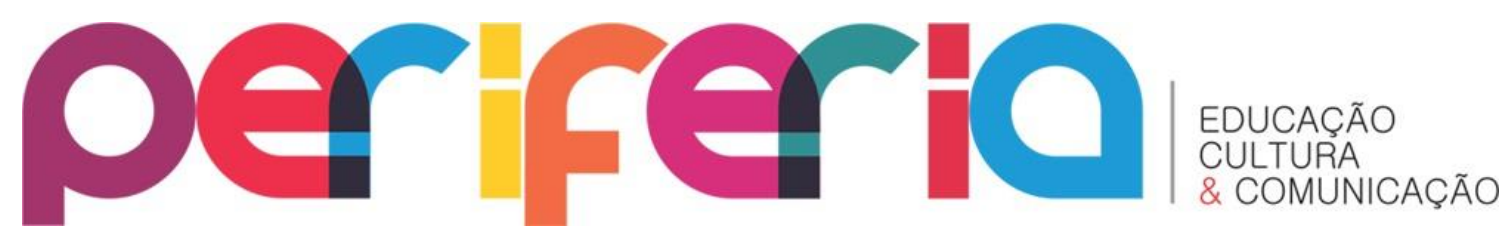

De fato, ao discutir as metamorfoses da "questão social", identificando, no curso da história, formas de uso do termo que o referiam mais diretamente aos problemas sociais concretos mais agudos em cada contexto - a intensa pobreza, o desemprego, a marginalidade - Castel acaba por mostrar que essa multiplicidade de significados, não raramente redutores, expressa variações históricas de sua significação que, consideradas em conjunto, acabam por evidenciar a própria variação dos modos hegemônicos como uma sociedade se interroga, em cada contexto, a respeito dos riscos de rompimento de sua coesão, ou seja, rompimento do modo instituído (e hegemonicamente aceito) de organizar a vida em sociedade.

É nesse sentido que a questão social, como diz o autor, "pode ser caracterizada por uma inquietação quanto à capacidade de manter a coesão de uma sociedade. A ameaça de ruptura é apresentada por grupos cuja existência abala a coesão do conjunto" (1998, p. 41).

Entendemos que um movimento de pensamento similar é feito por Saviani (2011) ao discutir “a educação como questão nacional”. Ao reconstituir o modo como a educação escolar foi sendo tratada no debate público e nas formulações jurídicas ao longo da história da oferta escolar, no Brasil, evidenciando a demora histórica da afirmação da escala nacional como referência para o delineamento da educação escolar como direito social (e, portanto, regido por regras de acesso e exercício ao menos formalmente válidas para todos e, nesse sentido, minimamente referidas a parâmetros de igualdade), o autor mostra que a "questão educacional", longe de se resumir aos problemas mais enfatizados em cada contexto - o analfabetismo, o "fracasso escolar", a “exclusão escolar" -, refere-se, a rigor, ao modo como uma sociedade se interroga a respeito da educação escolar facultada ao conjunto da população, envolvendo indagações não apenas a respeito do que se espera da educação escolar, mas também a respeito do que se está disposto a "tolerar" no que se refere às condições e formas de acesso à formação escolar para os diferentes segmentos sociais. 


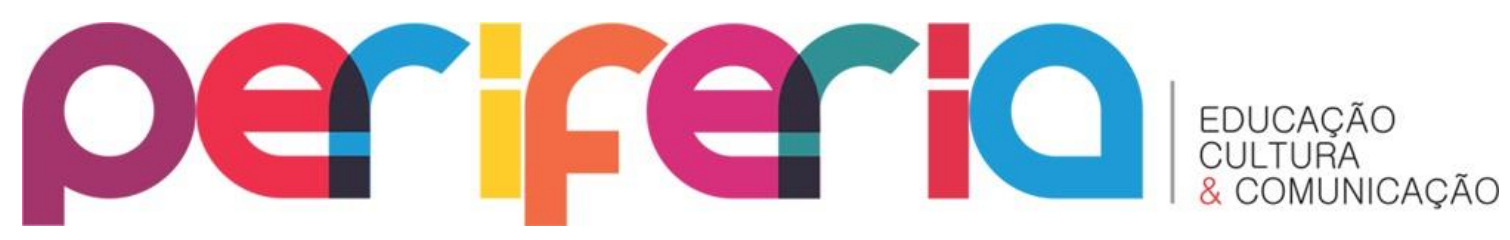

Essas considerações, ainda que muito breves e, portanto, com evidentes lacunas e simplificações, são fundamentais para expormos o ângulo a partir do qual buscamos apreender e problematizar a "educação especial na perspectiva da educação inclusiva", entendendo-a, antes de tudo, não simplesmente como uma política, mas, fundamentalmente, como um conjunto de formulações e práticas que, no curso de sua realização histórica, expressam as disputas reais que vêm ocorrendo em torno da concepção e da garantia do direito à educação escolar de crianças e jovens com deficiência.

É uma escolha de abordagem que nos leva a tomar a discussão das políticas públicas referidas ao tema como oportunidade para apreender a educação escolar de crianças e jovens com deficiência como questão, ou seja, como âmbito de indagação de uma sociedade a respeito de suas condições de convívio com determinados conjuntos de problemas historicamente concebidos como inerentes à vida privada, e de suas disposições de reconhecê-los e tratá-los como concernentes à vida pública, inscrevendo-os no âmbito dos direitos sociais.

\section{A EDUCAÇÃO DE CRIANÇAS E JOVENS COM DEFICIÊNCIA COMO PROBLEMA DA VIDA PÚBLICA NO BRASIL}

No Brasil, ainda que reconhecidas instituições no campo da educação especial tenham sido criadas na segunda metade do século XIX - como o Instituto Imperial dos Meninos Cegos, em 1854 (atual Instituto Benjamin Constant), e o Instituto dos Surdos-mudos, em 1857 (atual Instituto Nacional de Educação de Surdos), no Rio de Janeiro -, o acompanhamento, a educação e os cuidados em relação às pessoas com deficiência, por longo tempo, persistiram predominantemente como problema da vida privada. As famílias com condições econômicas favoráveis agenciavam diretamente os recursos e meios clínicos, terapêuticos e educacionais porventura existentes, enquanto as famílias da classe trabalhadora organizavam por conta dos próprios esforços suas redes de suporte e proteção, complementadas irregularmente, conforme 


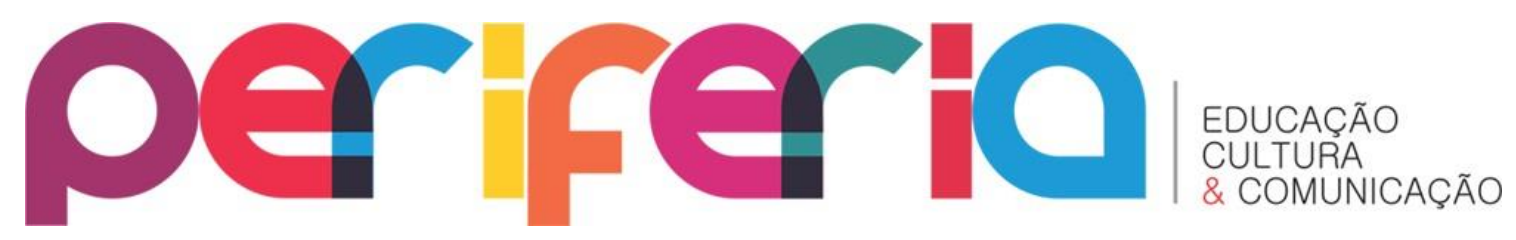

a localidade, por algum acesso, em geral esporádico, a serviços prestados isoladamente por instituições caritativas, filantrópicas ou públicas. Agravando esse quadro, dentre as instituições existentes, predominavam as de saúde mental e de educação caracterizadas por formas de atendimento clínico asilar e tutelar, que impunham aos internos sérios limites de convívio, de escolha e de desenvolvimento, incluindo, muitas vezes, formas cruéis de tratamento e apartação.

Só muito lentamente, ao longo do século XX, a “educação especial” foi se constituindo como um campo de gradual especialização de saberes, práticas, instituições e espaços, um campo que, até bem pouco tempo, se definia principalmente, em termos externos, por uma clara diferenciação em relação à educação regular, e, internamente, pelo caráter multifacetado do atendimento educacional relacionado aos diferentes tipos de deficiências.

Neste caso, as instituições ou classes que então realizavam o atendimento educacional especial formavam, como lembram Glat e Pletsch (2011), uma espécie de rede paralela em relação à educação regular. E essa “rede paralela", por sua vez, reunia, sem necessariamente inter-relacionar, uma grande variedade de instituiçõos que, segundo diversas e mesmo conflitantes origens, formas, concepções e práticas, cobriam um significativo leque de especificidades entendidas como deficiências. Assim, o acompanhamento, a educação e os cuidados em relação à pessoa com deficiência mantêm-se, por longo tempo, em uma situação de significativa indefinição entre responsabilidades privadas e responsabilidades públicas. A insuficiência, a variação e a fragmentação do atendimento educacional e das condições de acesso e frequência impõem a produção, no âmbito da vida privada, de estratégias e esforços que viabilizem a costura e a regularidade de acesso aos meios e recursos dispersos.

Ao longo do século XX, diferentes tentativas de inserção de crianças e jovens com deficiência no ensino regular foram experimentadas, predominando, porém, experiências pontuais e dispersas. Essa inserção só começa a adquirir posição de destaque na orientação de políticas 


\section{periferio}

educacionais, no Brasil, nas décadas de 1980 e 1990, quando aos poucos vai se intensificando o debate sobre a necessidade de modificação das instituições escolares regulares para que fossem produzidas melhores condições de participação dessas crianças e jovens nas relações e experiências formativas que nelas se realizavam.

O quadro brasileiro de debate público e de proposição de políticas relacionadas ao tema, a partir dessas décadas, é tensionado pela participação de diferentes forças sociais, institucionais e políticas, como os grupos de influência constituídos a partir das instituições comunitárias e filantrópicas com atuação na educação especial, como a Associação de Pais e Amigos de Excepcionais (APAE), a Sociedade Pestalozzi e congêneres; os grupos vinculados às lutas sociais relacionadas aos direitos das pessoas com deficiência; os movimentos profissionais e acadêmicos em defesa da educação pública e relacionados à educação especial; e as organizações internacionais, cuja posição no debate e orientação de políticas se torna crescentemente proeminente, expressando uma nova ordem política e econômica mundial que, especialmente a partir do fim da Segunda Guerra, implica alterações substantivas na atuação dos Estados nacionais ${ }^{4}$.

Neste último caso, é importante lembrar que os direitos das pessoas com deficiência e o direito à educação foram, nesse contexto, objeto de intensa discussão fomentada por organismos internacionais, dando origem a variados protocolos, instruções e orientações que foram sendo produzidos e difundidos por organizações como a Organização das Nações Unidas (ONU) e suas agências, a exemplo da Organização das Nações Unidas para a Educação, a Ciência e a Cultura (UNESCO), bem como por fóruns como os promovidos pela Organização dos Estados Iberoamericanos (OEI) ${ }^{5}$.

\footnotetext{
${ }^{4}$ Da vasta literatura a respeito das formas de participação de organizações internacionais no debate público e na orientação da formulação de políticas públicas, podemos destacar Coraggio (1996) e Dale (2004).

${ }^{5}$ Um exemplo importante, neste caso, é o "Word Programme of Action Concerning Disabled Persons" (Programa de Ação Mundial para as pessoas com Deficiência), expresso na Resolução $n^{\circ}$ 37/52 aprovada pela Assembleia Geral das Nações Unidas em 03 de dezembro de 1982,
} 


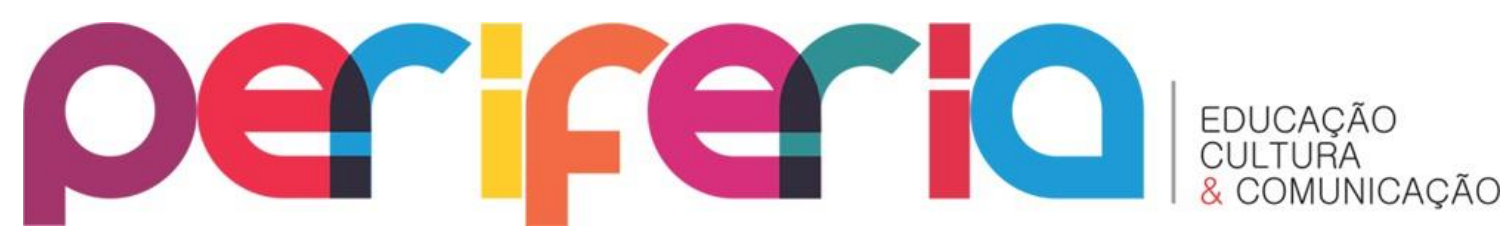

Assim, a intensificação da discussão e das proposições a respeito dos direitos das pessoas com deficiência, ocorrida nesse contexto, vai incorporando expectativas e ênfases produzidas em âmbitos variados, levando tanto ao aprofundamento das formulações sobre as especificidades das situações de deficiência, quanto à sua progressiva aproximação em relação aos direitos fundamentais então mais reconhecidos, como os direitos da criança e do adolescente e o direito à educação. As redes de difusão de preceitos e orientações aí constituídas passam a influir cada vez mais na definição de novos marcos referentes aos direitos educacionais das crianças e jovens com deficiência. E, na definição desses marcos, amplia-se progressivamente a ênfase na inserção dessas crianças e jovens na educação regular.

É nesse quadro que, a partir dos anos 1990, a educação de crianças e jovens com deficiência vai sendo progressivamente associada à noção de "educação inclusiva", aparecendo de forma cada vez mais forte em documentos internacionais que influiriam nas reformas educacionais em um vasto leque de países e, em particular, no Brasil, como a Declaração Mundial de Educação para Todos (1990) e a Declaração de Salamanca (1994).

O debate sobre "educação inclusiva", em curso a partir da década de 1970 nos Estados Unidos da América, mas verdadeiramente intensificado, em escala internacional, a partir da década de 1990, tem por foco, principalmente, a problematização da marginalização ou exclusão escolar relacionadas a um quadro histórico de acentuadas desigualdades econômicas e sociais, situação expressa pela persistência ou recrudescimento, em diversas sociedades (especialmente as de posição periférica nas relações capitalistas), de um significativo número de crianças que não ingressam na escola ou que dela saem sem ter efetivo acesso à formação escolar.

cuja versão em língua portuguesa está disponível, entre outros sítios, em: http://www2.camara.leg.br/atividade-legislativa/comissoes/comissoespermanentes/cdhm/comite-brasileiro-de-direitos-humanos-e-politicaexterna/ProgAcMundPessDef.html 


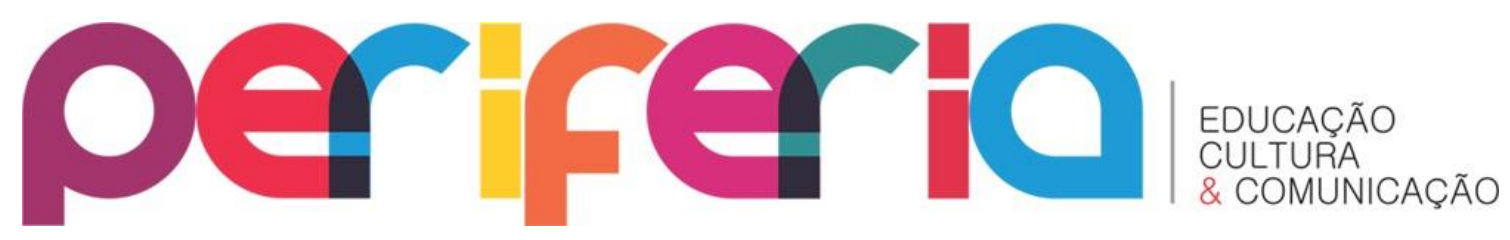

Autores como Ainscow (2009) lembram que, ainda que, em alguns países, a educação inclusiva seja vista principalmente "como uma forma de servir crianças com deficiência no ambiente da educação geral”, no plano internacional o termo tem sido usado com significação mais ampla, designando uma espécie de "reforma que apoia e acolhe a diversidade entre todos os estudantes", pautada no entendimento de que "o objetivo da inclusão educacional seja eliminar a exclusão social, que é consequência de atitudes e respostas à diversidade de raça, classe social, etnia, religião, gênero e habilidade" (AINSCOW, 2009, p. 11).

No interior desse debate, destaca-se a problematização da persistência de concepções e práticas em que as especificidades culturais, econômicas, físicas e intelectuais de determinados grupos ou sujeitos sociais são compreendidas como aspectos limitadores de sua participação em instituições ou classes comuns da escolarização regular, impedindo seu acesso a essas instituições ou ensejando formas de escolarização "alternativas", que implicam o acesso diferenciado à formação escolar e a fragmentação do convívio entre os diferentes grupos que deveriam ter a escola como um lugar de encontro, troca e efetiva formação compartilhada. Destaca-se, também, que, nesse quadro de realização da escolarização, as variações de desempenho escolar são predominantemente percebidas como intrinsecamente decorrentes da situação individual, familiar ou social do aluno, e não das limitações da própria sociedade e do próprio sistema escolar para relacionar-se com essas especificidades.

Reportando-se a essa problematização, a proposta de "educação inclusiva" se orienta pela compreensão de que a educação escolar, para constituir-se efetivamente como "direito humano e social", deve se caracterizar pela garantia de participação de todas as crianças numa mesma experiência de escolarização, entendendo-se a diferenciação das vias e condições de exercício do “direito à educação" como algo que reforça a própria diferenciação social que historicamente tem levado à disseminação de estigmas e de preconceitos, bem como à naturalização das desigualdades. 


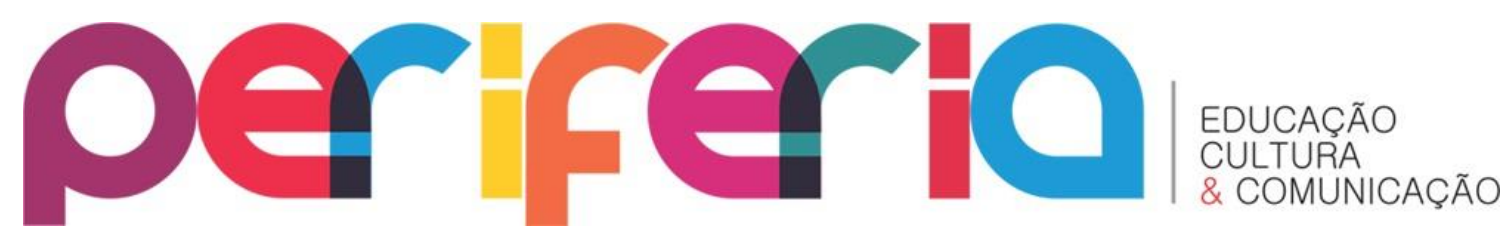

Assim, a proposta de "educação inclusiva" mostra-se, nos seus traços gerais e nos seus objetivos manifestos, compromissada com a universalização do acesso e da permanência escolar; com o reconhecimento do direito à educação como direito de participar de um processo e um circuito de convívio e formação plural; e com a consequente reorientação da escola regular no sentido da incorporação dos diferentes segmentos sociais, e da garantia de condições de participação efetiva do processo formativo escolar.

Pois bem, no interior desse debate e das proposições de educação inclusiva a ele relacionadas, a inclusão escolar de crianças e jovens com deficiência passa gradativamente a ocupar um lugar de destaque, definindose, primordialmente, como inclusão na escola regular.

No Brasil, essa formulação está presente na Constituição Federal de 1988, cuja redação original já prevê, como dever do Estado, a garantia de “atendimento educacional especializado aos portadores de deficiência, preferencialmente na rede regular de ensino" (art. 208, inciso III). Na LDB/96 essa disposição é reiterada e relativamente desenvolvida em um capítulo próprio (Capítulo V), que identifica a Educação Especial como uma modalidade de oferta de educação escolar a se realizar "preferencialmente na rede regular de ensino".

Mas as disposições decisivas no sentido da inclusão preferencial na rede regular se dão, principalmente, em meados dos anos 2000, quando as políticas vinculadas ao tema orientam-se para a intensificação do processo de inclusão educacional em turmas regulares, destacando-se, neste caso, a Política Nacional de Educação Especial na Perspectiva da Educação Inclusiva, instituída em 2008 e desdobrada por meio de uma expressiva quantidade de medidas dirigidas a sua implantação nos estados e municípios.

Em termos gerais, este deve ser reconhecido como um momento de alteração relevante da forma de problematização da educação escolar de pessoas com deficiência como problema pertinente à vida pública, implicando uma possibilidade de problematização igualmente contundente da educação escolar pública como um todo. Um momento que, em tese, pode ser 


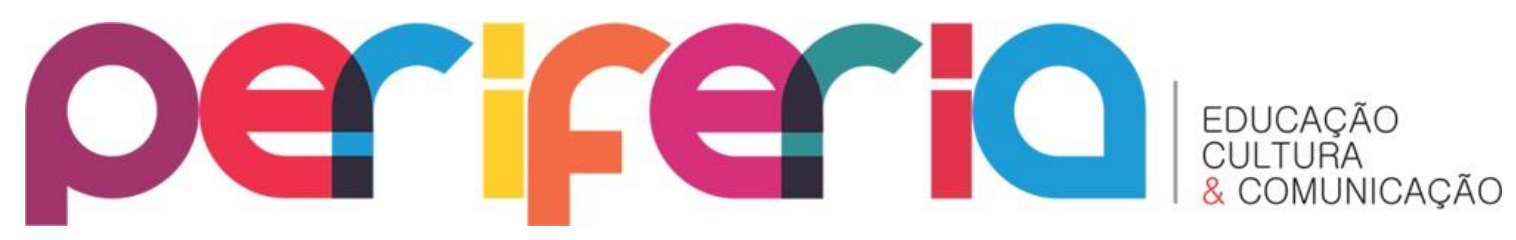

festejado, seja pela projeção das duas questões em uma nova escala, seja pelo novo tipo de indagação que projeta sobre as noções de direitos correlatas, seja, ainda, pela enunciação que parece portar de alteração nas políticas públicas no sentido da garantia efetiva de exercício desses direitos.

Os processos recentes de implantação e implementação da política concebida nessa perspectiva, porém, evidenciam relevantes contradições e fragilidades dos seus compromissos manifestos e dão visibilidade a limites históricos de sua realização cuja superação se mostra extremamente difícil, evidenciando que essas contradições, fragilidades e limites devem ser objeto de estudos e reflexões capazes de municiar as lutas sociais nos dois campos de direitos aqui referidos. A análise de alguns aspectos da "política praticada", abaixo apresentada, busca indicar alguns pontos necessários dessa discussão.

\section{A POLÍTICA PRATICADA}

A "Política Nacional de Educação Especial na Perspectiva da Educação Inclusiva", instituída em 2008, é um inegável marco referencial na decisiva orientação da inserção de crianças e jovens com deficiência na educação escolar regular, apresentando a "educação inclusiva" como um "paradigma educacional fundamentado na concepção de direitos humanos", expressivo de um "movimento mundial" "em defesa do direito de todos os alunos de estarem juntos, aprendendo e participando", e preconizando "a construção de sistemas educacionais inclusivos" em que "a organização de escolas e classes especiais passa a ser repensada, implicando uma mudança estrutural e cultural da escola para que todos os alunos tenham suas especificidades atendidas" (BRASIL, 2008, p. 1).

Tais orientações gerais, bem como seu desdobramento em disposições mais detalhadas, no corpo do documento, a respeito da inclusão em turmas regulares, passam, a partir de então, a aparecer sistematicamente em diversificadas medidas, menções, discursos e orientações por parte do 


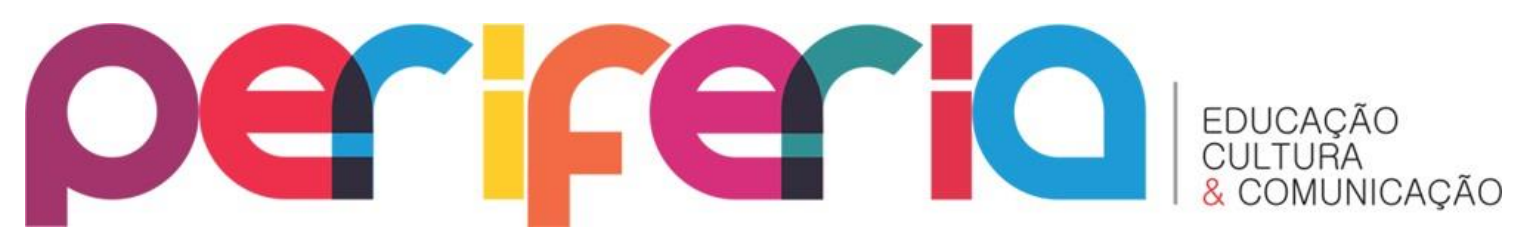

Governo Federal, incidindo decisivamente na pauta de debates, decisões e ações de estados e municípios.

Um marco internacional importante da instauração dessa política é a Convenção Internacional sobre os Direitos das Pessoas com Deficiência, aprovada em dezembro de 2006, pela Assembleia Geral da ONU, cujo texto final e seu Protocolo Facultativo são firmados em Nova lorque, em 30 de março de 2007. Essa Convenção se opõe à educação especial substitutiva ao ensino regular, preconizando a instauração de sistemas educacionais inclusivos, e a adesão do Brasil aos seus termos e orientações, em 2007, é imediatamente sucedida pela expedição de medidas que em pouco tempo dariam base jurídica e orientação institucional à nova concepção de direito à educação escolar.

A intensidade da atuação do Governo Federal nessa direção pode ser bem exemplificada pela sequência de medidas de peso expedidas nos três primeiros anos após a Convenção.

No início de 2007, o Brasil se torna um dos 127 países então signatários da Convenção e de seu Protocolo Facultativo, instituindo, no mesmo ano, um Grupo de Trabalho com a função de elaborar um documento norteador da Política Nacional; em setembro, é expedido o Decreto 6.215/2007, que estabelece o "Compromisso pela Inclusão das Pessoas com Deficiência", orientando a adesão voluntária dos estados e municípios a ações relacionadas às condições de inclusão das pessoas com deficiência em diferentes âmbitos da vida social e econômica, como educação, habitação, trabalho e mobilidade urbana; ainda em 2007, é lançado o Plano de Desenvolvimento da Educação (PDE), um plano de ação governamental que, em suas disposições, contrapõese ao paralelismo entre educação regular e educação especial.

Em 07 de janeiro de 2008, o Documento "Política Nacional da Educação Especial na Perspectiva da Educação Inclusiva”, produzido pelo GT instituído no ano anterior, é entregue ao Ministro da Educação; em seguida, o Decreto n¹86/2008 aprova o texto da Convenção e de seu Protocolo Facultativo; na sequência, o Decreto $n^{\circ}$ 6.571/2008 dispõe sobre o atendimento educacional 


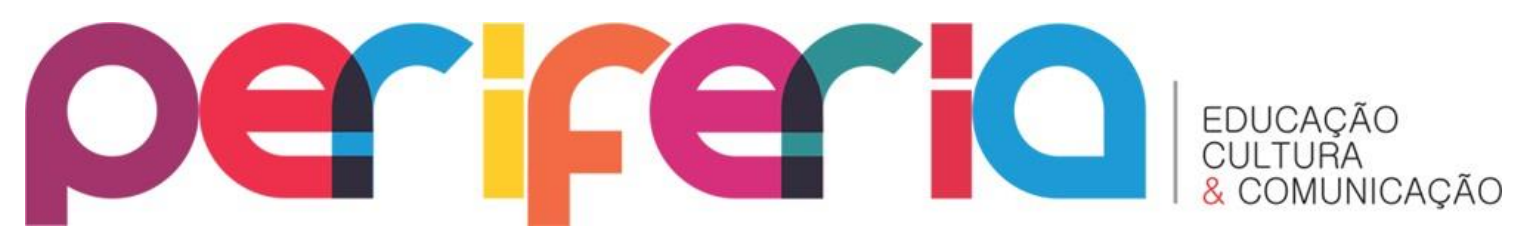

especializado, enfatizando a definição de critérios, referências e delimitações relativos à prestação de apoio técnico e financeiro da União aos sistemas de ensino.

Em 2009, o Decreto $n^{\circ} 6.949$ promulga integralmente as disposições da Convenção e de seu Protocolo Facultativo, comprometendo-se com sua execução; em seguida, é aprovada a Resolução n 4/2009, do Conselho Nacional de Educação, que "Institui Diretrizes Operacionais para o Atendimento Educacional Especializado na Educação Básica, modalidade Educação Especial", segundo a qual "os sistemas de ensino devem matricular os alunos com deficiência, transtornos globais do desenvolvimento e altas habilidades/superdotação nas classes comuns do ensino regular $e$ no Atendimento Educacional Especializado (AEE)" (Art. $1^{\circ}$, grifos nossos).

Desde então, as disposições sobre as modificações nos sistemas de ensino vinculadas à oferta de educação especial na rede regular já explicitavam variados aspectos das novas condições institucionais que seriam necessárias à inclusão especial, como a instituição do serviço denominado "atendimento educacional especializado" (AEE); a implantação de salas de recursos multifuncionais; a formação continuada de professores para o AEE; a formação de gestores, educadores e demais profissionais da escola para a educação inclusiva; a adequação arquitetônica de prédios escolares para acessibilidade; e a elaboração, produção e distribuição de recursos educacionais para a acessibilidade, incluindo-se, neste caso, materiais didáticos e paradidáticos em diferentes linguagens, bem como equipamentos para a comunicação e outras formas de apoio ao processo formativo escolar.

No entanto, nas disposições normativas posteriores a determinação de matrícula em escolas e classes regulares não é apenas reiterada, mas tratada com termos mais incisivos, destacando-se, neste caso, o Decreto $\mathrm{n}^{\circ}$ $7.611 / 2011$ que, substituindo o Decreto $n^{\circ}$ 6.571/2008 como normativa central relativa ao atendimento educacional especializado, define a "não exclusão do sistema educacional geral sob alegação de deficiência" (Art. $1^{\circ}$, 


\section{periferio}

inciso III) como "dever do Estado com a educação das pessoas público-alvo da educação especial".

Outro aspecto a destacar diz respeito à centralidade progressivamente conferida ao atendimento educacional especializado nas disposições sobre as condições e meios necessários à participação das crianças e jovens com deficiência na escolarização regular. Deve-se observar, neste caso, que, tal como alertado por autores como Garcia (2016), as medidas normativas relativas à educação especial falam com especificidade cada vez maior do AEE e de forma cada vez mais geral da escola regular, cujos problemas são predominantemente tratados em termos da "adaptação" física, funcional e pedagógica dos estabelecimentos de ensino, atribuindo-se um peso desproporcionalmente baixo à magnitude dos problemas que efetivamente marcam as condições gerais de realização da formação escolar pública, no Brasil. Nas palavras de Garcia, a ênfase nessas adaptações, nas peças condutoras dessa política,

Faz parecer que a organização social em curso e os processos educacionais a ela relacionados são exitosos, bastando apenas inserir todos os sujeitos humanos nessa corrente única, mediante um processo de 'eliminação de barreiras' à 'aprendizagem' e à 'participação plena'. (GARCIA, 2016, p. 16)

A realização de medidas relacionadas a essa política por parte dos estados e dos municípios revelaria de forma mais clara um complexo conjunto de problemas vinculados à centralidade da inclusão de crianças e jovens com deficiência na escola regular, problemas que, de nosso ponto de vista, estão certamente implicados com a formulação e a condução da Política Nacional, mas também, e de forma especialmente grave, com as condições históricas de configuração da administração pública e de exercício do poder político nos estados e municípios, que apresentam, por si, limitações bastante severas, entre outros aspectos, das condições institucionais e das disposições políticas para seu enfrentamento. 


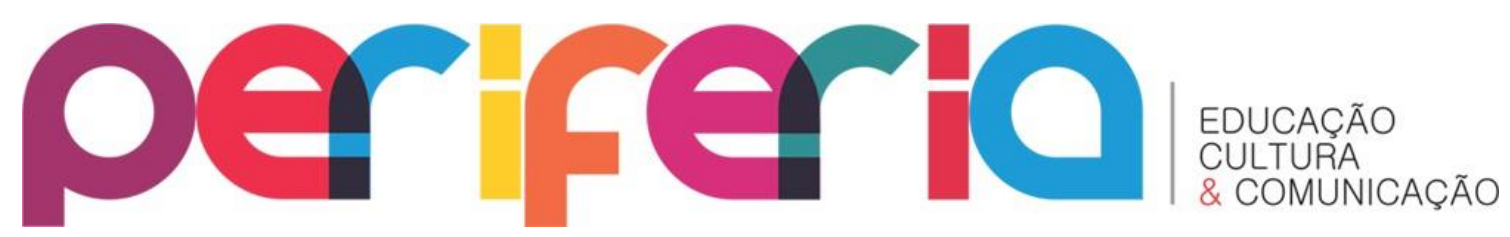

Não temos como desenvolver adequadamente, nos limites deste artigo, nossos argumentos a esse respeito, mas consideramos importante ao menos indicar alguns dos aspectos que temos em conta na apreciação desse campo de problemas. 0 debate sobre os limites dos estados e, especialmente, dos municípios, para a realização de políticas públicas, como as de educação, tem ressaltado a insuficiência de recursos desses níveis político-administrativos para tal fim. Esse não é um dado menor. Porém, é igualmente importante considerar que a limitação financeira é um aspecto fortemente implicado com outros de igual ou até superior relevância no que diz respeito aos modos históricos de participação dos estados e municípios na discussão e reconhecimento prático das suas responsabilidades com a realização de políticas públicas. A própria questão dos recursos públicos, por exemplo, envolve tanto problemas de distribuição entre os entes da Federação, quanto a intensa persistência de práticas verdadeiramente predadoras desses recursos por parte de diferentes níveis da administração pública.

Outro tipo de problema pode ser ilustrado pelo tipo de resistência de estados e municípios à implantação da Lei no 11.783, de 16 de julho de 2008, que institui o piso salarial profissional nacional para os profissionais do magistério público da educação básica, uma lei que precisa ser melhor reconhecida como uma conquista importante em um país cujo processo de expansão da oferta escolar jamais enfrentou desafios básicos ${ }^{6}$ de unificação dos sistemas parcelares de ensino, como o desafio de constituição de uma condição unificada de exercício e remuneração do trabalho educacional. Chama atenção, neste caso, a intensidade e o conteúdo da reação de estados e municípios à implantação não apenas do piso, mas também das novas disposições sobre a composição da jornada de trabalho, segundo as quais o limite máximo da carga horária para o desempenho das atividades de interação com os educandos seria de dois terços da carga total. Estados e municípios chegaram a acionar a Justiça contra essa disposição, embargando

\footnotetext{
${ }^{6}$ Uma discussão mais aprofundada desses desafios pode ser encontrada em Algebaile (2009).
} 


\section{periferio}

por quatro anos sua validade jurídica, alegando, dentre outros argumentos, que ela representava ingerência da União nas suas condições de administrar os sistemas públicos.

Pois bem, feitas essas considerações, reportamo-nos a alguns impasses relacionados à implantação e implementação das diretrizes da Política Nacional ${ }^{7}$, por parte de estados e municípios, que evidenciam problemas cujo estudo e discussão são fundamentais para avançarmos na compreensão dos desafios relacionados à educação escolar de crianças e jovens com deficiência.

Um primeiro aspecto a destacar, neste caso, diz respeito ao modo de encaminhamento das diretrizes da política nacional por parte de estados e municípios. Ainda que as experiências sejam diversas (e é importante não desprezar isto), é preciso reconhecer a significativa presença de formas de apreensão e condução da política fortemente comprometidas com propósitos de reajustes institucionais instrumentais à reorganização redutora da ação social do Estado. Nestes casos, a "adesão" à política nacional parece constituir um álibi para que alterações na oferta escolar sejam feitas de forma aligeirada, ampliando-se, de imediato, a matrícula, sem que tenham sido feitas as alterações nas condições de realização da escolarização e da formação escolar que forneçam bases adequadas para a efetiva "inclusão escolar" das crianças e jovens com deficiência.

Variados relatos descrevem processos de adoção do princípio da inclusão em escola regular feitos sem que sejam levadas em conta as bases objetivas necessárias a sua realização, desconsiderando-se as condições reais das escolas, dos sistemas de ensino e dos corpos profissionais disponíveis para o novo atendimento previsto e, por conseguinte, também se desconsiderando

\footnotetext{
${ }^{7}$ Trata-se de impasses observados a partir do acompanhamento que vem sendo realizado, pelos autores, de processos de implantação da inclusão em escola regular especialmente em municípios. Tal acompanhamento se dá por meio da participação em fóruns do campo educacional, da pesquisa direta de experiências municipais, ressaltando-se a pesquisa relacionada à Tese de Doutoramento realizada no PPFH/UERJ (ARAÚJO, 2017), e da revisão da literatura sobre o tema.
} 


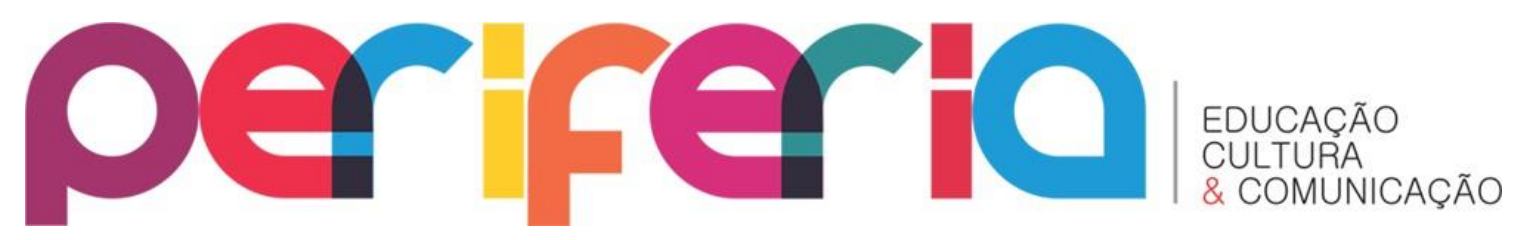

os efeitos cruéis desse processo sobre os supostos "sujeitos de direitos" dessas políticas.

Nesse quadro de ajuste aligeirado da oferta, uma das tensões centrais vem se constituindo em torno da ameaça ou tentativa de substituição dos espaços até então predominantes para o atendimento educacional $\mathrm{e}$ terapêutico especial (como as APAES e instituições congêneres) por formas de organização de oferta escolar pública, insuficientes para assegurar o acesso das pessoas com deficiência a um acompanhamento educacional e terapêutico plenos.

As tensões em torno dessa substituição envolvem componentes variados, como: a desestabilização das famílias, que se defrontam com o deslocamento do atendimento de seus filhos sem que fiquem claras as condições em que se darão as mudanças e as suas implicações; a desorientação de instituições e grupos profissionais que têm suas posições e condições de trabalho alteradas sem suficiente clareza sobre as novas condições e termos de atuação; a eclosão de rivalidades e encarniçadas disputas entre instituições e entre grupos profissionais que deveriam ser aproximados para construírem de forma compartilhada os processos de transição dos modelos de atendimento; a insuficiência de mecanismos regulares de diálogo e de trabalho associado ou complementar que ajude a reduzir o peso das rivalidades e disputas, e a fomentar o encadeamento de projetos e ações; o agravamento da impropriedade das condições materiais de realização do trabalho escolar; a tendência à homogeneização das deficiências, com a adoção de procedimentos genéricos de "inclusão" que implicam o aviltamento de variados aspectos do atendimento educacional do público-alvo desse processo, das ações do campo da saúde e da assistência que deveriam ser complementares, bem como da própria escola como unidade capaz de responder de forma condizente ao desafio.

Por sua vez, as experiências mais promissoras a cujo relato temos tido acesso mostram-se implicadas com os mesmos aspectos, mas na sua contraface, ou seja, revelando a pré-existência de bases institucionais mais 


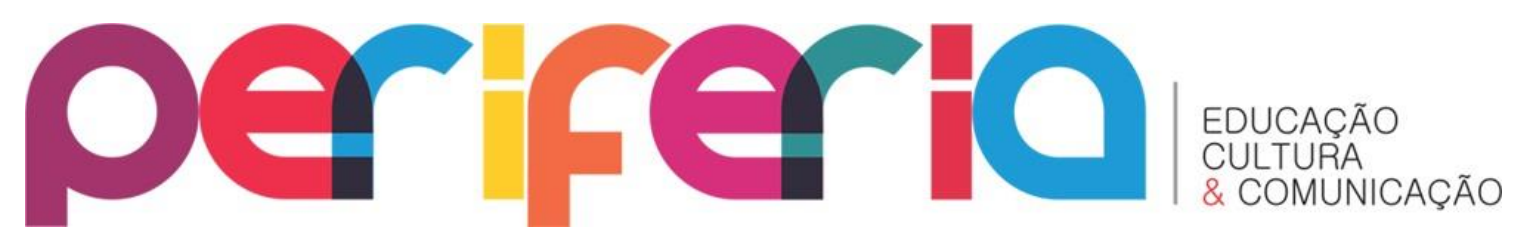

favoráveis à adoção e enfrentamento do novo desafio, bem como o engendramento de movimentações das administrações públicas e da sociedade civil que tentam sustentar o processo de mudanças na construção mais compartilhada das novas condições objetivas e subjetivas que elas requerem.

Porém, nos dois casos, dramaticamente, parece ficar evidente que as determinações federais de inclusão especial em escola regular, com todos os seus problemas e limites, constituem uma espécie de intervenção decisiva, sem a qual a educação de crianças e jovens com deficiência não teria assumido a visibilidade e o destaque que, agora, nos obriga a decifrá-la em novos termos.

\section{CONSIDERAÇÕES FINAIS: A EDUCAÇÃO ESPECIAL COMO QUESTÃO DA VIDA PÚBLICA}

O quadro de discussão do tema da educação de crianças e jovens, acima apresentado, traz preocupações e alertas relevantes, que em geral se vinculam à legítima percepção de pais e de profissionais da educação e de outras áreas, cujo envolvimento direto com as situações existenciais concretas de atendimento educacional, médico e terapêutico das crianças e jovens com deficiências leva a uma melhor identificação dos problemas e das mediações reais que devem ser levadas em conta nos projetos e nas práticas que se apresentam como de inclusão escolar.

Tais preocupações e alertas referem-se, em primeiro lugar, à constatação de que a "inclusão escolar" pode implicar a inserção das crianças e jovens com deficiências em ambientes material e subjetivamente despreparados para acolhê-los e para thes proporcionar relações sociais e com o conhecimento realmente adequadas e proveitosas, não apenas ao seu desenvolvimento visto pela ótica do aprendizado escolar, mas ao seu estar no mundo. 


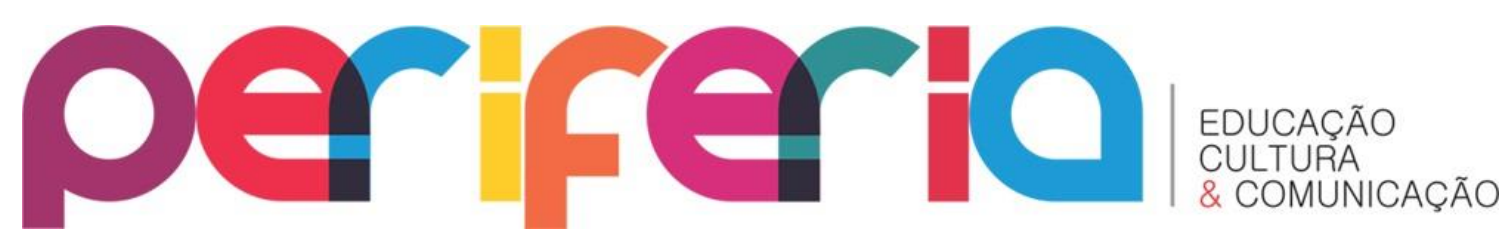

Em segundo lugar, referem-se à expectativa de que a "inclusão escolar" não represente simplesmente o desmonte das redes e práticas até então constituídas frente às omissões do Estado, sem que algo equivalente e melhor seja efetivamente colocado em seu lugar.

Por fim, referem-se, também, à compreensão de que a "inclusão escolar", a título de proporcionar uma escola para todos, não pode ignorar as múltiplas e por vezes profundas diferenças que requerem atenção, ação, tempo, espaço e condições definidas por relevantes especificidades.

Gostaríamos de afirmar que os fundamentos centrais da inclusão de alunos com deficiências na escolarização regular parecem-nos irrefutáveis. Nas sociedades modernas, cada vez mais o ingresso na escola regular representa, para todas as crianças e, portanto, também para as crianças e os jovens com deficiências, a possibilidade concreta de convívio e troca cotidiana com sua própria geração. Por outro lado, o ingresso das crianças com deficiência na escola regular também representa, para toda a população em idade escolar, a possibilidade concreta de um convívio e uma troca fundamentais para a formação de uma cultura de reconhecimento, respeito e acolhimento das diferenças, cuja existência não deveria ensejar estigmas, preconceitos e segregações.

E isto tem implicações particulares em um país como o Brasil, em que a rede escolar, por mais problemática que seja, é, efetivamente, a rede de serviço público mais difundida no território nacional e, portanto, ainda hoje, a única rede institucional em condições de possibilitar o acesso imediato à educação para um expressivo contingente de crianças e jovens com deficiências, que não encontrarão em suas localidades nenhuma instituição de convívio e formação similar.

Por essa condição de difusão, a rede escolar é também uma importante base para a organização e expansão gradual do atendimento médico, assistencial e educacional especializado necessário aos mais diferentes aspectos da vida das crianças e jovens com deficiências. Esse atendimento, por si, constitui um direito dessas crianças e jovens, e é lícito entender que 


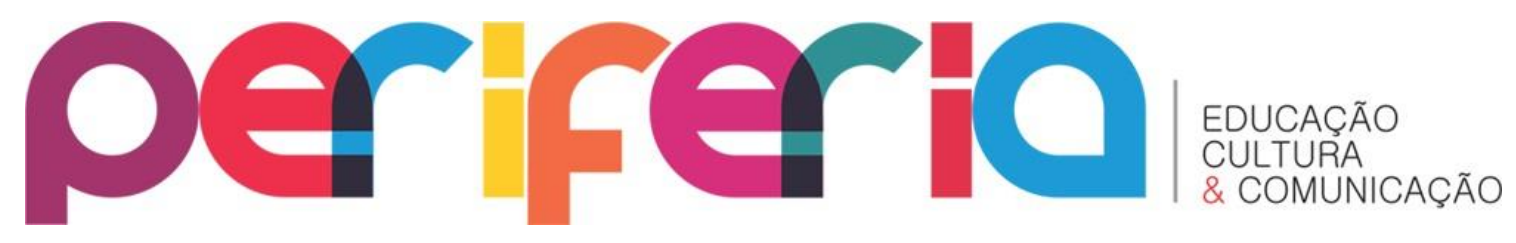

sua realização integrada à participação na educação escolar proporcione a essas crianças e jovens condições de participação social e de exercício de direitos que não seriam alcançadas por meio da realização isolada de cuidados médicos, assistenciais e educacionais.

A consideração desses fundamentos, no entanto, não pode se dar sem a rigorosa consideração simultânea das condições objetivas e subjetivas de sua conversão em projeto de ação governamental e em prática institucional, profissional, social.

Não se pode ignorar, por exemplo, que, apesar de ser a mais difundida rede de equipamentos e serviços públicos, no Brasil, a rede escolar brasileira tem debilidades tão profundas que, por si, impediriam que a inserção na educação escolar se desse na forma de uma efetiva inclusão.

Tendo isto em consideração, torna-se inevitável reconhecer que os encaminhamentos futuros dessa questão dependem, por certo, do aprimoramento das medidas governamentais que, porém, não se engendram por si, dependendo de mudanças substantivas nos modos de efetiva indagação social sobre o tema. Nesse sentido, o fato de que a educação escolar de crianças e jovens com deficiência tenha se consolidado no debate e na agenda política do país, constituindo-se como questão concernente à vida pública, ainda que com flagrantes insuficiências, equívocos e distorções, representa uma conquista que não pode ser desprezada nem contida nos limites da avaliação de políticas.

Há tarefas duras, certamente demoradas, que dizem respeito à própria disputa ampliada dos termos em que os mais diferentes segmentos sociais aceitam discutir a questão. Tarefas cujo enfrentamento, de nosso ponto de vista, requer empenhos crescentes em relação à participação central dos segmentos sociais e profissionais mais proximamente confrontados com as situações existenciais aí implicadas. Porque os mais objetivos problemas políticos e institucionais que precisam ser enfrentados estão inevitavelmente implicados com as condições subjetivas nas quais nossos sentimentos e indagações definem as diferenças entre o que consideramos inaceitável para 


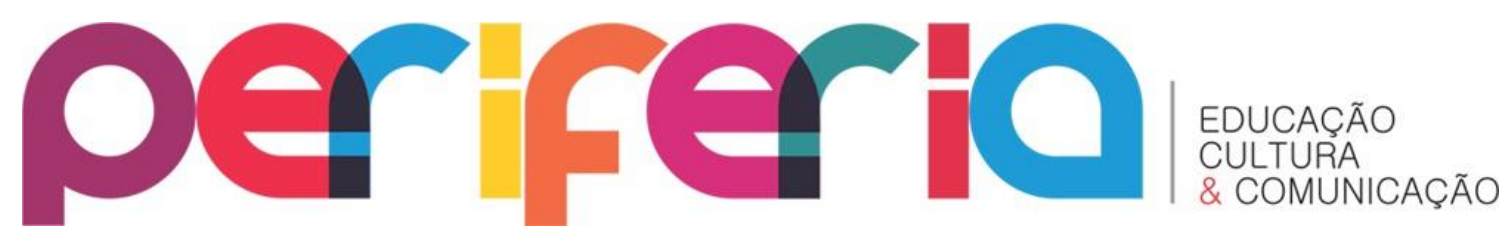

nossas próprias condições de vida, e o que estamos dispostos a tolerar para a vida dos outros.

\section{REFERÊNCIAS}

ALGEBAILE, Eveline. Escola pública e pobreza no Brasil: a ampliação para menos. Rio de Janeiro: Faperj / Lamparina, 2009.

ARAÚJO, Luiz Antonio. Pedagogia da inclusão: a arquitetura institucional da política de inclusão escolar de pessoas com deficiência no estado de Minas Gerais. 164 p. Tese de Doutorado em Políticas Públicas e Formação Humana. Universidade do Estado do Rio de Janeiro, 2016.

BRASIL. Política Nacional de Educação Especial na Perspectiva da Educação Inclusiva. Documento elaborado pelo Grupo de Trabalho nomeado pela Portaria $n^{\circ} 555 / 2007$, prorrogada pela Portaria $n^{\circ} 948 / 2007$, entregue ao Ministro da Educação em 07 de janeiro de 2008. Disponível em:

<http://portal.mec.gov.br/arquivos/pdf/politicaeducespecial.pdf>. Acesso em: 25/03/2013.

CASTEL, Robert. As metamorfoses da questão social: uma crônica do salário. Petrópolis, Vozes, 1998.

2008.

A discriminação negativa - Cidadãos ou autóctones? Petrópolis: Vozes,

CORAGGIO, José Luis. Proposta do Banco Mundial para a educação: sentido oculto ou problema de concepção? In: TOMMASI, Lívia de., et alii (orgs). 0 Banco Mundial e as Políticas Educacionais. São Paulo, Cortez, 1996.

DALE, Roger. Globalização e educação: demonstrando a existência de uma "Cultura Educacional Mundial comum" ou localizando uma "Agenda Globalmente Estruturada para a Educação"? In: Revista Educação e Sociedade, vol. 25, n. 87, maio/ago 2004, Campinas/SP: CEDES, 2004. p. 423-460.

FOUCAULT, Michel. Segurança, território e população. São Paulo: Martins Fontes, 2008.

GARCIA, Rosalba. M. C. educação especial na perspectiva inclusiva:

determinantes econômicos e políticos. Comunicações Piracicaba v. 23 n. 3 Número Especial p. 7-26, 2016. DOI: http://dx.doi.org/10.15600/2238121X/comunicacoes.v23nespp7-26

GLAT, Rosana; PLETSCH, Marcia Denise. Inclusão escolar de alunos com necessidades especiais. Rio de Janeiro: Eduerj, 2011. 


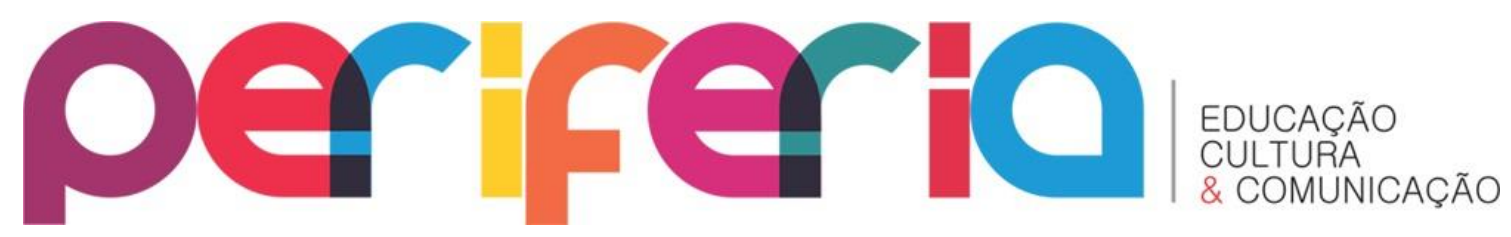

GRAMSCI, Antonio. Cadernos do cárcere. Volume 2. Os intelectuais. 0 princípio educativo. Jornalismo. Rio de Janeiro: Civilização Brasileira, 2000a. . Cadernos do cárcere. Volume 3. Maquiavel. Notas sobre o Estado e a política. Rio de Janeiro: Civilização Brasileira, 2000b.

Cadernos do cárcere. Volume 5. O Risorgimento. Notas sobre a história da Itália Rio de Janeiro: Civilização Brasileira, 2002.

SAVIANI, Dermeval. A nova Lei da educação: trajetória, limites e perspectivas. 12. ed. Campinas, SP: Autores Associados, 2011.

TELLES, Vera da Silva. Pobreza e cidadania. São Paulo: Editora 34, 2001. 